\title{
TINGKAT PENERAPAN KESELAMATAN, KESEHATAN KERJA DAN LINGKUNGAN (K3L) PADA PROYEK KONSTRUKSI
}

\author{
Johan Oberlyn Simanjuntak ${ }^{1}$, Partahi Lumbangaol ${ }^{2}$, Salomo Simanjuntak ${ }^{3}$, \\ Humisar Pasaribu ${ }^{4}$, Okto Simanungkalit ${ }^{5}$ \\ Fakultas Teknik Universitas HKBP Nommensen, Medan \\ Email: oberlyn.simanjuntak@yahoo.co.id ${ }^{1}$, partahi@yahoo.com $_{4}^{2}$, \\ Salomojuntak679@yahoo.com ${ }^{3}$, pasaribu.humisar@yahoo.com ${ }^{4}$
}

\begin{abstract}
Increased development in various regions in Indonesia, especially in the city of Medan, makes many contactors compete with each other in implementing a project. Starting from the time, quality, and cost. However, there are still many contractors who ignore Occupational Safety, Health and Environment $(K 3 L)$. This study aims to determine the level of application of Occupational Safety, Health and Environment (K3L) in construction projects. Occupational Health, Safety and Environment (K3L) is a program that aims to create a safe, healthy workplace. So that it can reduce the risk of work accidents and occupational diseases as low as possible on the project.

The theory used in this study uses quantitative methods that tend to produce descriptive results. The sampling technique was carried out by observation and questionnaire. The instrument used comes from the Minister of Public Works Regulation No. 9 of 2008. This research was conducted on the Cinema Grand Jati Junction construction project located on Jln Perintis Kemerdekaan, Medan

The results of the research on the level of application of Occupational Safety, Health, and Environment (K3L) for the Cinema Grand Jati Junction construction project on Jln Perintis Kemerdekaan, Medan amounted to $90.54 \%$. The completeness of K3L facilities in the project was $86.7 \%$.
\end{abstract}

Keywords : Safety, Occupational Health and Environment, Project safety support facilities and PPE, Construction Projects

\section{PENDAHULUAN}

Beberapa proyek konstruksi di Indonesia banyak terjadi di kota besar salah satunya kota Medan. Dalam pengerjaan proyek selain memperhatikan ketepatan waktu, mutu, dan biaya, perusahaan konstruksi perlu juga memperhatikan keselamatan,kesehatan kerja dan lingkungan (K3L) di proyek.

Menurut data Jamsostek jumlah kecelakaan kerja pada tahun 2017 sebanyak 123 ribu kasus kecelakaan kerja. Keselamatan kerja mengandung arti bagaimana cara seseorang 
untuk menjaga diri atau orang lain karena beban kerja yang ada di lapangan mengharuskan seorang pekerja mendapat perlindungan tersebut agar mereka dapat bekerja secara maksimal.

Berdasarkan uraian di atas maka penerapan keselamatan, kesehatan kerja dan Lingkungan (K3L) yang baik diperlukan untuk meminimalisir kecelakaan dalam bekerja khususnya di proyek konstruksi. Maka perlu adanya penelitian Tujuan yang ingin dicapai dari penelitian adalah: mengetahui penerapan keselamatan, kesehatan kerja dan lingkungan (K3L) pada proyek yang diteliti; mengetahui kelengkapan fasilitas pendukung penerapan keselamatan, kesehatan kerja dan lingkungan (K3L) di proyek yang diteliti.

\section{TINJAUAN PUSTAKA}

\section{KESELAMATAN KERJA}

Pengertian program kesehatan kerja: "Keselamatan kerja menunjukkan pada kondisi yang aman atau selamat dari penderitaan, kerusakan atau kerugian di tempat kerja" (Mangkunegara, 2000:161). Leon C Meggison yang dikutip oleh Mangkunegara (2000:161) bahwa istilah keselamatan mencakup kedua istilah yaitu resiko keseamatan dan resiko kesehatan.

Tindakan keselamatan kerja bertujuan untuk menjamin keutuhan dan kesempurnaan, baik jasmani maupun rohani manusia, serta hasil kerja dan budaya tertuju pada kesejahteraan masyarakat pada umumnya. Keselamatan kerja manusia secara terperinci antara meliputi : pencegahan terjadinya kecelakaan, mencegah dan atau mengurangi terjadinya penyakit akibat pekerjaan, mencegah dan atau mengurangi cacat tetap, mencegah dan atau mengurangi kematian, dan mengamankan material, konstruksi, pemeliharaan, yang kesemuanya itu menuju pada peningkatan taraf hidup dan kesejahteraan umat manusia.

\section{KESEHATAN KERJA}

Pengertian program kesehatan kerja menunjukkan pada kondisi yang bebas dari gangguan fisik, mental, emosi atau rasa sakit yang disebabkan oleh lingkungan kerja. Kesehatan kerja menurut Manulang (1995:89) adalah bagian dari ilmu kesehatan yang 
bertujuan agar tenaga kerja memperoleh keadaan kesehatan yang sempurna baik fisik, mental maupun sosial sehingga memungkinkan dapat bekerja secara optimal. Upaya kesehatan kerja adalah penyerasian antara kapasitas kerja, beban kerja dan lingkungan kerja agar setiap pekerja dapat bekerja secara sehat tanpa membahayakan dirinya sendiri maupun masyarakat di sekitarnya. Beberapa sebab yang memungkinkan terjadinya kecelakaan dan gangguan kesehatan pekerja (Mangkunegara, 2000:163 ) yaitu :
a. Keadaan tempat lingkungan kerja
b. Pengaturan penerangan
c. Pemakaian peralatan kerja
d. Kondisi fisik dan mental pekerja

Usaha-usaha untuk mencegah dan mengendalikan tekanan di dalam tempat kerja dapat dijalankan dengan cara (Ranupandojo dan Husnan, 2002:264) sebagai berikut:
a. Mencari sumber dari tekanan.
b. Mencari media yang menjadi alat penyebaran tekanan tersebut.
c. Memberi perawatan khusus pada karyawan yang menderita tekanan tersebut

\section{KESELAMATAN DAN KESEHATAN KERJA (K3)}

Keselamatan dan Kesehatan Kerja merupakan instrumen yang memproteksi pekerja, perusahaan, lingkungan hidup, dan masyarakat sekitar dari bahaya akibat kecelakaan kerja. Perlindungan tersebut merupakan hak asasi yang wajib dipenuhi oleh perusahaan. K3 bertujuan mencegah, mengurangi, bahkan menihilkan risiko kecelakaan kerja (zero accident). Penerapan konsep ini tidak boleh dianggap sebagai upaya pencegahan kecelakaan kerja dan penyakit akibat kerja yang menghabiskan banyak biaya (cost) perusahaan, melainkan harus dianggap sebagai bentuk investasi jangka panjang yang memberi keuntungan yang berlimpah pada masa yang akan datang (Prasetyo, 2009).

\section{KECELAKAAN KERJA}

Yang dimaksudkan dengan kecelakaan adalah kejadian yang merugikan yang tidak terduga dan tidak diharapkan dan tidak ada unsur kesengajaan. Kecelakaan selalu dapat 
terjadi karena berbagai sebab. Menurut Budiono (2003:14) mengemukakan indikator Keselamatan, Kesehatan Kerja dan Lingkungan (K3L), meliputi :

- Faktor manusia/pribadi

- Faktor kerja/lingkungan

- Lingkungan kerja

- Alat kerja dan bahan

- Cara melakukan pekerjaan

\section{A. Peraturan Mengenai Keselamatan, Kesehatan, Kerja dan Lingkungan (K3L)}

Sistem K3L adalah pengelolaan K3L dengan menerapkan sistem manajemen untuk mencapai hasil yang efektif dalam mencegah kecelakaan dan efek lain yang merugikan.

\section{Peraturan Menteri PU No. 9 Tahun 2008}

Pada bab 3 peraturan menteri PU nomor 9 tahun 2008 pasal 4 dijelaskan tentang ketentuan penyelenggaraan Keselamatan, Kesehatan Kerja dan Lingkungan (K3L) di bidang konstruksi, adapun ketentuannya sebagai berikut:

1. Kegiatan jasa konstruksi yang dilaksanakan oleh pengguna jasa/penyedia jasa terdiri dari jasa pemborongan, jasa konsultasi dan kegiatan swakelola yang aktifitasnya melibatkan tenaga kerja dan peralatan kerja untuk keperluan pelaksanaan pekerjaan fisik di lapangan wajib menyelenggarakan K3L konstruksi bidang pekerjaan umum.

2. Penyelenggaraan K3L Konstruksi Bidang Pekerjaan Umum wajib menggunakan pedoman ini beserta lampirannya

3. Penyelenggaraan K3L Konstruksi Bidang Pekerjaan Umum dikelompokkan menjadi 3 (tiga) kategori, yaitu:
a) Risiko Tinggi
b) Risiko Sedang
c) Risiko Kecil

Kinerja penerapan penyelenggaraan K3L Konstruksi Bidang Pekerjaan Umum dibagi mencapai 3 (tiga), yaitu 

a. Baik, bila mencapai hasil penilaian $>85 \%$;
b. Sedang, bila mencapai hasil penilaian $60 \%-85 \%$;
c. Kurang, bila mencapai hasil penilaian $<60 \%$.

\section{Fasilitas Kesehatan dan Keselamatan Kerja}

\section{A.1 Macam-Macam Alat Pelindung Diri (APD)}

Alat-alat pelindung diri yang standar pada proyek konstruksi ada berbagai macam, antara lain:

1. Helm proyek

2. Masker

3. Pakaian kerja

4. Sarung tangan

5. Sepatu

6. Safety Belt Safety belt
7. Jas Hujan (Rain Coat)

8. Kaca Mata Pengaman (Safety Glasses)

9. Penutup Telinga (Ear Plug)

10. Pelindung Wajah (Face Shield)

11. P3K (Pertolongan Pertama pad Kecelakaan).

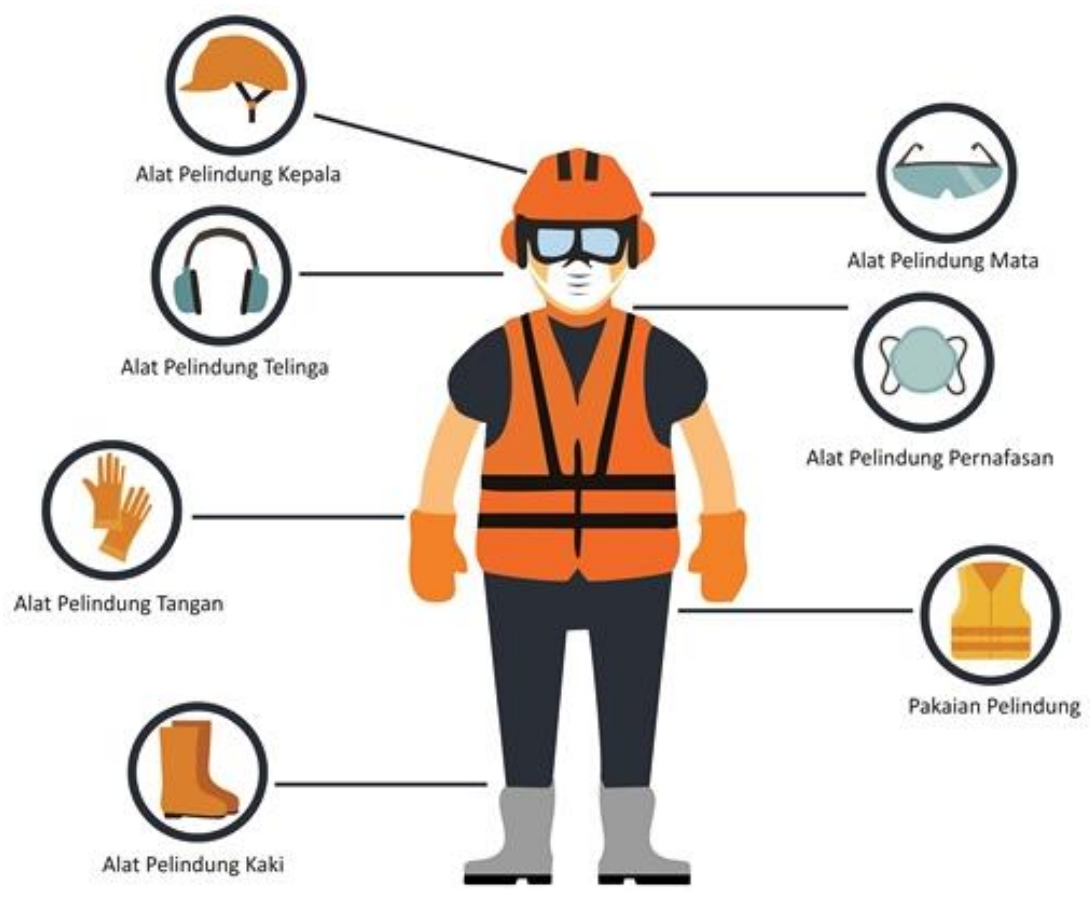


Gambar 1. Beberapa Alat Pelindung Diri (APD)

\section{A.2 Macam-Macam Fasilitas Pengaman Proyek}

Selain adanya APD maka perlu juga dilengkapi oleh alat pengaman pada proyek konstruksi yang gunanya untuk menunjang keamanan pada proyek tersebut, seperti :

1. Jaring pengaman,

2. Rambu-rambu,

3. Hydrant,

4. Spanduk peringatan $\mathrm{K} 3$,

5. Alarm peringatan,

6. Lampu peringatan,

7. Jalur Eksekusi.

\section{B. Indikator Tingkat Penerapan K3L}

Berikut ini adalah kisi-kisi instrumen untuk penelitian pelaksanaan Tingkat Penerapan Keselamatan, Kesehatan Kerja dan Lingkungan (K3L) :

Tabel 1. Pendidikan dan Pelatihan

\begin{tabular}{|c|c|c|c|c|c|c|}
\hline \multirow{2}{*}{ No } & \multirow{2}{*}{ Pertanyaan } & \multicolumn{5}{|c|}{ Nilai } \\
\hline & & 1 & 2 & 3 & 4 & 5 \\
\hline A1 & Perusahaan mengadakan pendidikan dasar bagi para pegawai & & & & & \\
\hline \multirow{2}{*}{ A2 } & Perusahaan mengadakan pelatihan K3 untuk pelaksanaan & & & & & \\
\hline & pekerjaan yang berpotensi bahya & & & & & \\
\hline A3 & Perusahaan mengadakan pelatihan Khusus untuk para mandor & & & & & \\
\hline A4 & Anda merasakan manfaat dari pendidikan dan pelatihan K3 & & & & & \\
\hline A5 & $\begin{array}{l}\text { Perusahaan mengadakan pelatihan mengenai pertolongan pertama saat } \\
\text { kecelakaan }(\mathrm{P} 3 \mathrm{~K})\end{array}$ & & & & & \\
\hline
\end{tabular}

Tabel 2. Publikasi K3

\begin{tabular}{|c|l|c|c|c|c|c|}
\hline \multirow{2}{*}{ No } & \multicolumn{1}{|c|}{ Pertanyaan } & \multicolumn{3}{|c|}{ Nilai } \\
\cline { 3 - 5 } & \multicolumn{1}{|c|}{} & 1 & 2 & 3 & 4 & 5 \\
\hline B1 & Perusahaan telah melakukan sosialisasi tentang program K3 & & & & \\
\hline B2 & Perusahaan telah melakukan sosialisasi tentang penggunaan & & & & \\
\hline
\end{tabular}




\begin{tabular}{|c|l|l|l|l|l|}
\cline { 2 - 5 } B3 & Alat perlindungan Diri & & & & \\
\hline & perusahaan telah melakukan sosialisasi tentang Penggunaan & & & & \\
\hline & alat pemadam kebakaran (APAR) & & & & \\
\hline B4 & $\begin{array}{l}\text { Perusahaan telah melakukan sosialisasi tentang prosedur keselamtan } \\
\text { kerja untuk pelaksana pekerjaan yang berpotensi bahaya }\end{array}$ & & & \\
\hline B5 & Pemasangan tanda peringatan di tempat yang berpotensi bahaya & & & & \\
\hline B6 & $\begin{array}{l}\text { Di lingkungan perusahaan terdapat pesan-pesan tentang keselamatan } \\
\text { kerja }\end{array}$ & & & \\
\hline B7 & Perusahaan memberikan informasi tentang tingkat bahaya pekerjaan & & & \\
\hline
\end{tabular}

Tabel 3. Kontrol Lingkungan Kerja

\begin{tabular}{|c|c|c|c|c|c|c|}
\hline \multirow{2}{*}{ No } & \multirow{2}{*}{ Pertanyaan } & \multicolumn{5}{|c|}{ Nilai } \\
\hline & & 1 & 2 & 3 & 4 & 5 \\
\hline $\mathrm{C} 1$ & Suhu ruangan cukup baik & & & & & \\
\hline $\mathrm{C} 2$ & Kondisi ventilasi, pendingin, penerangan cukup baik & & & & & \\
\hline $\mathrm{C} 3$ & Pemeriksaan kesehatan secara berkala & & & & & \\
\hline $\mathrm{C} 4$ & Pemeriksaan kondisi APD, APAR, sistem hidrant secara berkala & & & & & \\
\hline C5 & Perusahaan menyediakan P3K & & & & & \\
\hline C6 & Kontrol sumber resiko di tempat kerja dan lingkungan & & & & & \\
\hline \multirow{2}{*}{$\mathrm{C} 7$} & Perbaikan/mengganti instalasi, ruang, peralatan kerja yang & & & & & \\
\hline & menimbulkan bahaya jika teridentifikasi memiliki potensi bahaya & & & & & \\
\hline
\end{tabular}

Tabel 4. Pengawasan dan Disiplin

\begin{tabular}{|c|c|c|c|c|c|c|}
\hline \multirow{2}{*}{ No } & \multirow{2}{*}{ Pertanyaan } & \multicolumn{5}{|c|}{ Nilai } \\
\hline & & 1 & 2 & 3 & 4 & 5 \\
\hline D1 & Pengecekan terlebih dahulu alat-alat sebelum digunakan & & & & & \\
\hline $\mathrm{D} 2$ & Kewajiban penggunaan APD & & & & & \\
\hline D3 & Pengecekan alat-alat K3 secara berkala & & & & & \\
\hline D4 & Pemberlakuan peraturan dan pemberian Sanksi & & & & & \\
\hline D5 & Memberikan pengawasan terhadap bahan-bahan berbahaya & & & & & \\
\hline D6 & Perusahaan mempunyai peraturan & & & & & \\
\hline D7 & Ada departemen khusus yang menangani K3L & & & & & \\
\hline
\end{tabular}

\section{Statistical Product and Service Solution (SPSS)}


Gambaran tentang cara kerja komputer dengan program SPSS dalam mengolah data

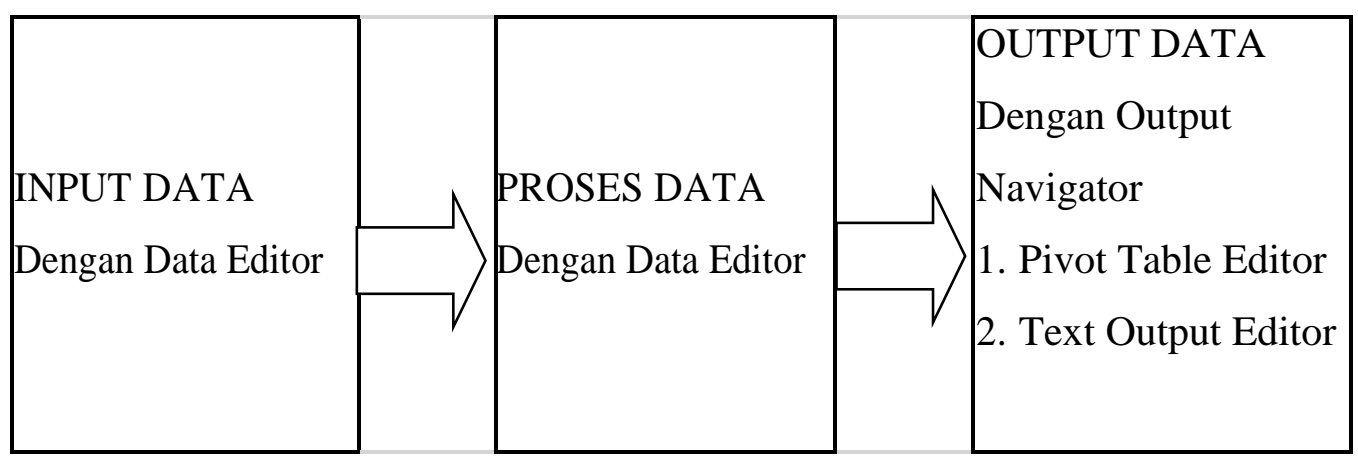

Gambar 2. Diagram Prosedur SPSS

\section{C.1 Pengujian Validitas}

Uji validitas dilakukan untuk memastikan seberapa baik suatu instrument digunakan untuk mengukur konsep yang seharusnya diukur. Tinggi rendahnya validitas suatu angket dihitung dengan teknik korelasi, dengan rumus:

$$
\operatorname{Rxy}=\frac{N \Sigma X Y-(\Sigma X)(\Sigma Y)}{\sqrt{\left\{N \Sigma X 2-(\Sigma X)^{2}\right\}\left\{N \Sigma Y 2-(\Sigma Y)^{2}\right.}}
$$

Dimana :

$\mathrm{R} x y=$ Angka Indeks Korelasi Product Moment

$\mathrm{N}=$ Jumlah sampel

$\sum \mathrm{x}=$ Jumlah nilai data $\mathrm{x}$

$\sum \mathrm{y}=$ Jumlah nilai data $\mathrm{y}$

$\sum_{\mathrm{xy}}=$ jumlah hasil perkalian antara skor $\mathrm{x}$ dan $\mathrm{y}$

\section{C.2 Pengujian Reabilitas}

Suharsimi Arikunto (2006) menyatakan "Reliabilitas menunjuk pada suatu pengertian bahwa sesuatu instrument cukup dapat dipercaya untuk digunakan sebagai alat pengumpul data karena instrument tersebut sudah baik". Uji reliabitas dilakukan dengan rumus cronbach alpha sebagai berikut

$$
\mathrm{R}_{11=}\left[\frac{K}{K-1}\right]\left[1-\frac{\sum \sigma \mathrm{b}^{2}}{\sigma \mathrm{t}^{2}}\right]
$$


Dimana:

r11 = Reabilitas yang dicari

$\mathrm{K}$ = Banyaknya butir pertanyaan

$\sum \sigma \mathrm{b}^{2}=$ Jumlah varian butir

$\sum \sigma \mathrm{t}^{2}=$ Varian total

Apabila koefisien Cronbach'sAlpha (r11) $\geq 0.7$ maka dapat dikatakan instrumen tersebut reliable (Johnson \& Christensen, 2012).

\section{C.3 Pengujian Rentang (Range)}

Dalam sekelompok data kualitatif akan terdapat data dengan nilai terbesar dan nilai terendah. Rentang (range) adalah selisih antara data dengan nilai tertinggi dengan nilai terendah. Maka perhitungannya adalah sebagai berikut:

$$
\text { Range }=\frac{\text { Skor terting } g i-\text { skor terendah }}{\text { skor }}
$$

Keterangan:

Range $=$ Selisih skor tertinggi dengan skor terendah dibagi range skor

Skor tertinggi $=5$

Skor terendah $=1$

\section{METODE PENELITIAN}

Penelitian ini dilakukan pada proyek pembangunan Cinema Grand Jati Junction yang terdiri dari 7 lantai. Didalam melaksanakan survei pada penelitian ini dilakukan dengan menggunakan kuesioner sebagai alat pengumpulan data.

Berikut penjelasan tahapan-tahapan yang dilakukan dalam penelitian ini:

1. Studi pendahuluan dan literatur

Berisikan tentang Latar belakang, perumusan masalah, dan batasan masalah:

a. Memilih masalah yang diteliti.

b. Merumuskan, membatasi masalah, menentukan tujuan dan manfaat, kemudian melakukan studi pendahuluan. 
2. Landasan Teori

a. Menyajikan kajian pustaka/referensi untuk mendukung teori utama.

b. Menguji sebuah teori yang telah mapan.

3. Observasi

a. Observasi langsung yaitu dengan meminta data-data langsung ke proyek.

b. Wawancara yaitu melakukan tanya jawab secara langsung dengan pembimbing di proyek.

4. Penyebaran Kuisioner

5. Menginput data hasil dari penyebaran kuisioner serta melakukan rekapitulasi data.

6. Analisa dan Pembahasan

Berapa besar tingkat penerapan K3L di proyek konstruksi terkait dan fasilitas pendukung keselamatan, kesehatan kerja dan lingkungan (K3L) pada proyek yang diteliti sudah sesuai dengan yang dipersyaratkan.

7. Kesimpulan dan Saran.

\section{Metode Pengumpulan Data}

Jenis kuosioner yang digunakan dalam penelitian ini dipandang dari bentuknya yaitu

a. Kuisioner pilihan ganda yaitu sama dengan kuisioner tertutup, responden tinggal memilih jawaban yang tersedia

b. Kuisioner isian yaitu sama dengan kuisioner terbuka, responden diberi kesempatan untuk menjawab dengan kalimatnya sendiri.

c. Chek list yaitu sebuah daftar pertanyaan dimana responden tinggal menghubungkan tanda chek (v) pada kolom yang sesuai.

d. Rating scale yaitu sebuah pertanyaan yang diikuti oleh kolom- kolom yang menunjukkan tingkatan, misalnya mulai sangat baik sampai sangat kurang baik. 


\section{Metode Analisa Data}

Pengukuran kuesioner ini dilakukan dengan skala Likert dimana responden diberi beberapa pilihan (options) yang kemudian tinggal memilih derajat kesetujuan/ketidaksetujuannya atas pertanyaan yang diajukan. Nilai dari skala Linkert tersebut adalah :

a. Jawaban jika tersedia, layak, dan lengkap diberi nilai 5 (100\%)

b. Jawaban jika tersedia, tidak layak, dan lengkap diberi nilai 4 (80\%)

c. Jawaban jika tersedia, layak, dan tidak lengkap diberi nilai $3(60 \%)$

d. Jawaban jika tersedia, tidak layak, dan tidak lengkap diberi nilai 2 (40\%)

e. Jawaban jika tidak tersedia diberi nilai $1(20 \%)$

\section{ANALISIS DAN HASIL}

\section{Pengujian Data}

Berikut ini merupakan hasil pengujian validitas data kuesioner dengan menggunakan program IBM SPSS Statistics 23 :

a. Pendidikan dan Pelatihan

Hasil pengujian validitas dalam Pendidikan dan Pelatihan dinyatakan valid dan dapat digunakan karena memiliki nilai $r$ hitung $0.638>0.443$

b. Publikasi K3

Hasil pengujian validitas dalam Publikasi K3 dinyatakan valid dan dapat digunakan karena memiliki nilai $\mathrm{r}$ hitung $0.555>0.443$

c. Kontrol Lingkungan Kerja

Hasil pengujian validitas dalam Kontrol Lingkungan Kerja dinyatakan valid dan dapat digunakan karena memiliki nilai $r$ hitung $0.546>0.443$

d. Pengawasan dan Disiplin

Hasil pengujian validitas dalam Pengawasan dan Disiplin dinyatakan valid dan dapat digunakan karena memiliki nilai $r$ hitung $0.506>0.443$.

e. Peningkatan Kesadaran K3 
Hasil pengujian validitas pada tabel 9 menunjukan semua pernyataan yang ada dalam Peningkatan Kesadaran K3 dinyatakan valid dan dapat digunakan karena memiliki nilai $r$ hitung $0.545>0.443$.

\section{Menentukan Persentase Kuesioner}

Berikut ini merupakan hasil penghitungan penentuan persentase tingkat penerapam keselamatan,kesehatan kerja dan lingkungan (K3L) pada:

A. Pendidikan dan Pelatihan

Tabel 5 Hasil Persentase (\%) Pendidikan dan Pelatihan

\begin{tabular}{|c|c|c|c|c|c|}
\hline \multirow{2}{*}{ RESPONDEN } & \multicolumn{5}{|c|}{ Nilai Pertanyaan } \\
\cline { 2 - 6 } & A1 & A2 & A3 & A4 & A5 \\
\hline Total & 92 & 91 & 95 & 90 & 87 \\
\hline Jumlah Total & 455 \\
\hline
\end{tabular}

Hasil Hasil Persentase (\%) menunjukan pernyataan yang ada dalam Pendidikan dan Pelatihan dinyatakan baik karena memiliki persentase $91 \%$.

B. Publikasi K3

Tabel 6 Hasil Persentase (\%) Publikasi K3

\begin{tabular}{|c|c|c|c|c|c|c|}
\hline \multirow{2}{*}{ RESPONDEN } & \multicolumn{7}{|c|}{ Nilai Pertanyaan } \\
\cline { 2 - 7 } & B1 & B2 & B3 & B4 & B5 & B6 \\
\hline Total & 90 & 90 & 95 & 92 & 87 & 92 \\
\hline Jumlah Total \\
\hline \multicolumn{7}{|c|}{ persentase = jumlah total/ jumlah kebijakan (\%) } \\
\hline
\end{tabular}

Hasil Hasil Persentase (\%) menunjukan pernyataan yang ada dalam Publikasi K3 dinyatakan baik karena memiliki persentase $91 \%$.

C. Kontrol Lingkungan Kerja

Tabel 7 Hasil Persentase (\%) Kontrol Lingkungan Kerja

\begin{tabular}{|l|c|c|c|c|c|c|c|}
\hline \multirow{2}{*}{ RESPONDEN } & \multicolumn{7}{|c|}{ Nilai Pertanyaan } \\
\cline { 2 - 7 } & $\mathrm{C} 1$ & $\mathrm{C} 2$ & $\mathrm{C} 3$ & $\mathrm{C} 4$ & $\mathrm{C} 5$ & $\mathrm{C} 6$ & $\mathrm{C} 7$ \\
\hline
\end{tabular}




\begin{tabular}{|l|l|l|l|l|l|l|r|}
\hline \multicolumn{1}{|c|}{ Total } & 87 & 87 & 92 & 95 & 90 & 90 & 91 \\
\hline Jumlah Total & \\
\hline persentase $=$ jumlah total/ jumlah kebijakan (\%) \\
\hline
\end{tabular}

Hasil Hasil Persentase (\%) menunjukan pernyataan yang ada dalam Kontrol Lingkungan Kerja dinyatakan baik karena memiliki persentase $90.3 \%$.

D. Pengawasan dan Disiplin

Tabel 8 Hasil Persentase (\%) Pengawasan dan Disiplin

\begin{tabular}{|c|c|c|c|c|c|c|c|}
\hline \multirow{2}{*}{ RESPONDEN } & \multicolumn{7}{|c|}{ Nilai Pertanyaan } \\
\cline { 2 - 8 } & D1 & D2 & D3 & D4 & D5 & D6 & D7 \\
\hline Total & 91 & 88 & 92 & 92 & 89 & 91 & 88 \\
\hline Jumlah Total \\
\hline \multicolumn{10}{|c|}{ persentase = jumlah total/ jumlah kebijakan (\%) } & 90.143 \\
\hline
\end{tabular}

Hasil Hasil Persentase (\%) menunjukan pernyataan yang ada dalam Pengawasan dan Disiplin dinyatakan baik karena memiliki persentase $90.143 \%$.

E. Peningkatan Kesadaran K3

Tabel 9 Hasil Persentase (\%) Peningkatan Kesadaran K3

\begin{tabular}{|c|c|c|c|c|c|}
\hline \multirow{2}{*}{ RESPONDEN } & \multicolumn{5}{|c|}{ Nilai Pertanyaan } \\
\cline { 2 - 6 } & E1 & E2 & E3 & E4 & E5 \\
\hline Total & 93 & 92 & 92 & 90 & 93 \\
\hline Jumlah Total & 460 \\
\hline
\end{tabular}

Hasil Hasil Persentase (\%) menunjukan pernyataan yang ada dalam Peningkatan

Kesadaran K3 dinyatakan baik karena memiliki persentase $92 \%$.

Tabel 10. Hasil perhitungan data dari beberapa item yang dinilai:

\begin{tabular}{|c|l|c|c|}
\hline No Item & \multicolumn{1}{|c|}{ Variabel } & $\%$ & keterangan \\
\hline 1 & Pendidikan dan Pelatihan (A) & 91 & Baik \\
\hline 2 & Publikasi K3 (B) & 92 & Baik \\
\hline 3 & Kontrol Lingkungan Kerja (C) & 90.28 & Baik \\
\hline 4 & Pengawasan dan Disiplin (D) & 90.14 & Baik \\
\hline 5 & Peningkatan Kesadaran K3 (E) & 92 & Baik \\
\hline
\end{tabular}




\begin{tabular}{|l|l|l|}
\hline Jumlah & 455.42 & \\
\hline Persentase Total (Jumlah/Total Variabel) & 91.084 & Baik \\
\hline
\end{tabular}

\section{Hasil Observasi}

Berikut ini merupakan hasil pengujian Observasi yang telah di dapatkan dari proyek pembangunan Cinema Grand Jati Junction yang berada di Jln. Perintis Kemerdekaan, Medan.

\section{Observasi Penerapan K3L}

Tabel 11 Hasil Observasi Penerapan K3L

\begin{tabular}{|c|c|c|c|c|c|c|c|}
\hline \multirow{3}{*}{ NO } & URAIAN & \multirow{2}{*}{\multicolumn{5}{|c|}{ Skor yang ada }} & \multirow{3}{*}{$\begin{array}{c}\text { Nilai } \\
5\end{array}$} \\
\hline & \multirow{3}{*}{\begin{tabular}{|l|}
\multicolumn{1}{|c|}{ Pertanyaan } \\
Apakah Penyedia Jasa mempunyai Kebijakan K3L? \\
Apakah Pimpinan Perusahaan Penyedia jasa menandatangani \\
Kebijakan K3L? \\
\end{tabular}} & & & & & & \\
\hline & & 1 & 2 & 3 & 4 & 5 & \\
\hline B & & 1 & 2 & 3 & 4 & 5 & 5 \\
\hline \multicolumn{8}{|c|}{ Apakah Kebijakan K3L penyedia jasa telah memenuhi ketentuan sebagai berikut: } \\
\hline $\mathrm{C}$ & $\begin{array}{l}\text { Sesuai dengan sifat dan kategori risiko K3L bagi penyedia } \\
\text { jasa? }\end{array}$ & 1 & 2 & 3 & 4 & 5 & 4 \\
\hline $\mathrm{D}$ & $\begin{array}{l}\text { Mencakup komitmen untuk mencegah kecelakaan Kerja } \\
\text { dan penyakit akibat kerja serta peningkatan berkelanjutan } \\
\text { K3L? }\end{array}$ & 1 & 2 & 3 & 4 & 5 & 4 \\
\hline $\mathrm{E}$ & $\begin{array}{l}\text { Mencakup komitmen mematuhi peraturan dan persyaratan } \\
\text { lain yang terkait dengan K3L? }\end{array}$ & 1 & 2 & 3 & 4 & 5 & 4 \\
\hline $\mathrm{F}$ & $\begin{array}{l}\text { Digunakan sebagai kerangka untuk menyusun dan } \\
\text { mengkaji sasaran K3L? }\end{array}$ & 1 & 2 & 3 & 4 & 5 & 5 \\
\hline $\mathrm{G}$ & Didokumentasikan, diterapkan, dan dipelihara? & 1 & 2 & 3 & 4 & 5 & 4 \\
\hline $\mathrm{H}$ & $\begin{array}{l}\text { Dikomunikasikan kepada semua personil yang bekerja } \\
\text { dibawah pengendalian penyedia jasa agar peduli terhadap } \\
\text { K3L? }\end{array}$ & 1 & 2 & 3 & 4 & 5 & 5 \\
\hline $\mathrm{I}$ & Dapat diakses oleh semua pihak yang berkepentingan? & 1 & 2 & 3 & 4 & 5 & 5 \\
\hline $\mathrm{J}$ & $\begin{array}{l}\text { Dievaluasi secara berkala untuk memastikan bahwa kebijakan } \\
\text { K3L masih relevan dan sesuai? }\end{array}$ & 1 & 2 & 3 & 4 & 5 & 4 \\
\hline
\end{tabular}




\begin{tabular}{|l|c|c|c|c|c|c|}
\hline Jumlah & & & & & 45 \\
\hline Jumlah Total ( jumlah x 20\%) & 900 & & & & & \\
\hline persentase = jumlah total/ jumlah item yang dinilai (\%) & 90 & & & & & \\
\hline
\end{tabular}

Dari hasil observasi nilai K3L didapatkan yaitu;

Tabel 12. Tingkat Penerapan K3L

\begin{tabular}{|c|l|c|c|}
\hline NO & \multicolumn{1}{|c|}{ URAIAN } & PERSENTASE & KETERANGAN \\
\hline 1 & Safety Pstchology & $91.08 \%$ & Baik \\
\hline 2 & Observasi Penerapan K3L & $90 \%$ & Baik \\
\hline \multicolumn{3}{|l|}{} \\
\hline \multicolumn{2}{|l|}{ Jumlah Persentase } & $181.08 \%$ & Baik \\
\hline
\end{tabular}

\section{Observasi Pengadaan APD}

Tabel 13 Hasil Observasi Pengadaan APD

\begin{tabular}{|c|c|c|c|c|c|c|c|}
\hline No & \multicolumn{6}{|c|}{ Item yang dinilai } & \multirow{2}{*}{ Nilai } \\
\hline 1 & Alat Pelindung Diri (APD) & \multicolumn{5}{|c|}{ Skor yang ada } & \\
\hline & Helm Proyek & 1 & 2 & 3 & 4 & 5 & 5 \\
\hline & Sepatu & 1 & 2 & 3 & 4 & 5 & 5 \\
\hline & Sarung Tangan & 1 & 2 & 3 & 4 & 5 & 4 \\
\hline & Rompi & 1 & 2 & 3 & 4 & 5 & 5 \\
\hline & Masker & 1 & 2 & 3 & 4 & 5 & 4 \\
\hline & Safety Belt & 1 & 2 & 3 & 4 & 5 & 4 \\
\hline & Jas Hujan & 1 & 2 & 3 & 4 & 5 & 3 \\
\hline & Kaca Mata Pengaman & 1 & 2 & 3 & 4 & 5 & 4 \\
\hline & Penutup Wajah & 1 & 2 & 3 & 4 & 5 & 4 \\
\hline & Pelindung Telinga & 1 & 2 & 3 & 4 & 5 & 3 \\
\hline 2 & Fasilitas Pengaman Proyek & & & & & & \\
\hline & Jaring Pengaman & 1 & 2 & 3 & 4 & 5 & 5 \\
\hline & Rambu-Rambu & 1 & 2 & 3 & 4 & 5 & 5 \\
\hline & Hydrant & 1 & 2 & 3 & 4 & 5 & 4 \\
\hline & Spanduk Peringatan K3L & 1 & 2 & 3 & 4 & 5 & 4 \\
\hline & Kotak Obat (P3K) & & & & 4 & 5 & 5 \\
\hline & Jalur Evakuasi & & & & 4 & & 4 \\
\hline
\end{tabular}




\begin{tabular}{|c|c|c|c|c|c|c|}
\hline Alaram Peringatan & 1 & 2 & 3 & 4 & 5 & 5 \\
\hline Lampu Peringatan & 1 & 2 & 3 & 4 & 5 & 5 \\
\hline Jumlah & & & & & & 78 \\
\hline Jumlah Total ( jumlah x 20\%) & 1560 & & & & & \\
\hline $\begin{array}{l}\text { persentase }=\text { jumlah total } / \text { jumlah } \\
\text { item yang dinilai }(\%)\end{array}$ & 86.7 & & & & & \\
\hline
\end{tabular}

\section{KESIMPULAN}

Kesimpulan yang dapat diambil pada penelitian tentang tingkat penerapan Keselamatan, Kesehatan Kerja,dan Lingkungan (K3L) pada proyek pembangunan Cinema Grand Jati Junction yang berada di Jln Perintis Kemerdekaan, Medan adalah:

1. Tingkat penerapan keselamatan,kesehatan kerja dan Lingkungan memiliki angka rata-rata sebesar 90.54\%. Angka ini dikategorikan BAIK dalam tingkat penerapan K3L diproyek.

2. Dilihat dari kelengkapan fasilitas $\mathrm{K} 3 \mathrm{~L}$ yang tersedia pada proyek pembangunan Cinema Grand Jati Junction yang berada di Jln Perintis Kemerdekaan, Medan memiliki angka kisaran sebesar 86.7\%. Angka ini dikategorikan BAIK dalam hal kelengkapan fasilitas K3L di proyek.

\section{DAFTAR PUSTAKA}

Ervianto W.I.2005. Manajemen proyek kontruksi:Yogyakarta

Husen, Akbar 2009. Mamajemen Proyek, Andi: Yogyakarta

Peraturan Menteri Pekerjaan Umum No. 9 Tahun 2008

Peraturan Pemerintah No. 5 Tahun 2012

Sunindhia, Y.W dan Widianti Ninink. 1987. Dmanajemen tenaga kerja, Bina Aksara: Jakarta

Setiawan, Ade dkk. Pelaksanaan Sistem Manajemen Keselamatan dan Kesehatan Kerja (SMK3) Pada Proyek Pembangunan Hotel Ibis Padang Sumatera Barat. Universitas Bung Hatta:Padang 